\title{
PRESSÃO URBANA EM ÁREAS DE FLORESTAS: história e conflitos políticos da proteção ambiental
}

\author{
Profa. Dra. Neli Aparecida de Mello-Théry \\ Instituto de Estudos Avançados, Programas de Pós graduação em Geografia Humana e Ciência Ambiental \\ Escola de Artes, Ciências e Humanidades da Universidade de São Paulo \\ Av. Arlindo Béttio, 1000. Ermelino Matarazzo. 03828-000 - São Paulo - SP, Brasil \\ Tel: (11) 3091-1027=namello@usp.br \\ Msc. Benedito Oscar Correia \\ oscarcorreiab@bol.com.br
}

\begin{abstract}
RESUMO
O objetivo deste artigo é analisar como o processo de urbanização na cidade de São Paulo resultou em pressão sobre as florestas urbanas, tomando-se o Parque da Serra da Cantareira e a APA Capivari-Monos como objetos do estudo de caso. As duas unidades de conservação foram escolhidas por serem núcleos da Reserva da Biosfera do Cinturão Verde de São Paulo (RBCV), atualmente um dos instrumentos da política ambiental. No processo histórico de substituição das florestas por outros usos do solo, apontam-se as fragilidades que estas regiões possuem e também a sua importância para a preservação de espécies da flora e da fauna. Constituíram literatura básica e marcos da análise, os documentos de criação da Reserva, as visitas de campo, as entrevistas com responsáveis pela gestão das unidades e as opiniões de autores reconhecidos.
\end{abstract}

Palavras-chaves: Urbanização, Parque da Serra da Cantareira, Capivari-Monos, pressão antrópica

\begin{abstract}
The aim of this article is to analyze how the process of urbanization in the city of Sao Paulo resulted in pressure on urban forests, taking the Parque da Serra da Cantareira and APA Capivari as objects of the study. The two protected areas were chosen because they constitute part of the Biosphere Reserve of the Green Belt of São Paulo (RBCV), currently one of the instruments of environmental policy. In the historical process of replacement of forests with other land uses, point to the weaknesses that these regions have as well as importance for the preservation of species of flora and fauna. Constituted basically literature, the documents establishing the Reserve, field visits, interviews with responsible management and opinions of authors recognized.
\end{abstract}

Key words: Urbanization, Park Cantareira, APA Capivari-Monos, Anthropogenic Pressure

\section{RESUMEN}

Este artículo analisa cómo el proceso de urbanización en la ciudad de São Paulo resultó en una presión sobre los bosques urbanos. Por este motivo, estudiaremos los casos del Parque Serra da Cantareira y la APA Capivari-Monos.Las dos unidades de conservación fueron escogidos por el hecho de que son núcleos de Reserva de la Biósfera del Cinturón Verde de São Paulo (RBCV), uno de los instrumentos actuales de la Política Ambiental. El proceso histórico de sustitución de los bosques por otros usos del suelo apunta las fragilidades que estas regiones así como su importáncia para la preservación de especies de flora y fauna. Constituiran literatura basica y marcos de analisis, los documentos de creación de la Reserva, las visitas de campo, las entrevistas con responsables por la gestión de las unidades y las opiniones de autores reconocidos.

Palabras-Claves: Urbanización, Parque Estadual da Serra da Cantareira, APA Capivari-Monos, Presión Antrópica

\section{Introdução}

A temática da ecologia, que nos últimos anos vêm recebendo atenção de grande parte da sociedade, tem aberto oportunidades inestimáveis para a realização de estudos interdisciplinares. O “meio ambiente contém inúmeras possibilidades para a compreensão das relações entre Estado e sociedade, no passado e no presente" (MARTINEZ, 2007, p. 16). Mais precisamente no "mundo ocidental, desde o último quartel do século XX, essas relações passaram por um processo de redefinição" (MARTINEZ, 2007, p. 16). O desmatamento, a contaminação por agrotóxicos dos cursos dos rios, o assoreamento dos mesmos, 
o processo de extinção de espécies da fauna e da flora e as formas de ocupação das terras, etc., nos levam a entender que estes fenômenos não são estudos exclusivos de uma única área do saber. As ciências humanas lentamente vêm saindo do confinamento acalentado pelo positivismo. O saber ambiental exige uma postura multidisciplinar, ele nos leva a entender que o conhecimento amplo só é alcançado com a interdisciplinaridade. A problemática ambiental também recebe contribuições importantes de geógrafos, biólogos, arqueólogos, geólogos, historiadores, etc.. A relação paradoxal entre desenvolvimento e conservação ambiental exige esta nova postura da comunidade científica. O questionamento de conceitos construídos na história e a formulação de novos conceitos auxiliam sobejamente as questões ambientais.

Dois núcleos da Reserva da Biosfera do Cinturão Verde de São Paulo foram selecionados para o estudo das relações pressão antrópica - exclusão social. As regiões do Parque Estadual da Cantareira (PEC) e APA Capivari-Monos, aqui estudadas não são exceções, pelo contrário, elas só confirmam a regra citada acima, em função da relação complexa existente entre o meio urbano As regiões da Serra da Cantareira e APA Capivari-Monos sofrem pressões antrópicas, fruto da urbanização desordenada impetrada em São Paulo, quando da mudança do eixo econômico do campo para a urbe.

\section{A complexa relação do Parque da Cantareira e APA Capivari-Monos com a Cidade de São Paulo}

O Parque da Cantareira (pequena porção da Serra da Cantareira) e a Capivari-Monos (APA), limites do meio urbano paulista, ao norte e ao sul respectivamente, sofrem sérias dificuldades para manteremse intactas, apesar de cada uma apresentar especificidades em relação ao modelo de ocupação. Porém, não são somente as classes mais pobres que ameaçam os limites das duas áreas. A especulação imobiliária obtem alta lucratividade com os condomínios ou loteamentos de alto padrão, preservando um aparente "verde", para que estas regiões se "configurarem além do cimento, asfalto, carros e pessoas" (AYRES, 2008, p. 51). Outros por completa necessidade ocupam pequenos espaços nas encostas das serras (Serra da Cantareira) ou no seu interior (APA), para terem onde viver e morar, problema que afeta, entre outros, as áreas de mananciais, demonstrando a ausência do poder público.

Ao tratarmos do processo de urbanização, tendo como objeto de estudo as duas áreas queremos chamar a atenção para a história complexa da preservação, destacando as relações de interesses que compõe este panorama. Além de tratar do processo histórico desta urbanização, identificar os sujeitos deste processo, verificar seus interesses, perceber como se processam as resistências, também tentaremos reconstruir as políticas públicas ambientais.

Não obstante, a desarticulação entre políticas públicas não é o único fator que determinou e determina a degradação ambiental existente, porém, esta, ao longo dos séculos tem sido preponderante para atingirmos quase o desaparecimento da Mata Atlântica.

Para autores como Trepl (2002), a noção de meio ambiente é associada a problemas e somente veio a ser construída em meados do século passado, garantindo, portanto a noção de que são questões socialmente construídas. Neste período o conceito de meio ambiente ganhou força tanto no meio científico quanto social e começou a ser uma demanda que parcelas organizadas da sociedade defendem. $\mathrm{Na}$ verdade, durante séculos, o estímulo que se dava era à produção, sem se preocupar com as conseqüências sobre o meio ambiente.

Em Fazendeiros e Pioneiros de São Paulo, Pierre Monbeig mostra toda a dinâmica que transformou o estado de São Paulo em um dos motores do desenvolvimento brasileiro. Da mesma maneira, outro clássico, A ferro e fogo de Warren Dean (1996) mostra que desde a chegada no Brasil, os colonizadores e novos migrantes tudo faziam para transformar a mata em um sistema produtivo e, mais tarde, como a mesma serviu de fonte de energia para o desenvolvimento da indústria. Silva (1976) destacou como os capitais oriundos da cafeicultura transformaram-se em base da indústria paulista. Janes Jorge (2007) põe em relevo quanto o processo de urbanização de São Paulo, mercantil e elitista ao extremo, degradou o ambiente. Portanto, ao resgatarmos apenas estes quatro autores tem-se o respaldo de que a cidade 
paulatinamente transformou-se em metrópole mundial. Por último, Milton Santos em A urbanização brasileira salienta que a metrópole de São Paulo, com seu avanço técnico-científico e informacional tornou-se uma urbe ubíqua, fazendo-se presente em todo território brasileiro.

Para Damiani (2004) "a cidade de São Paulo transforma-se de "taipa de pilão, da época colonial, à cidade do tijolo, nesta passagem do fim do séc. XIX ao início do séc. XX, a importância do café, da industrialização, da ferrovia, depois do bonde elétrico e uma extraordinária especulação imobiliária, envolvendo o Centro [...] Pierre Monbeig menciona uma epidemia de urbanização" (DAMIANI, 2005, p. 21). São Paulo, desde os primórdios da colonização era uma pequena Vila no interior do Brasil, a qual tinha um papel estratégico de rasgamento do território brasileiro, seja para o apresamento de índios com o propósito de usá-los como mão de obra escrava, seja para as viagens de reconhecimento do território.

Este papel sofreu profundas alterações com o advento do café em São Paulo. Primeiramente, ele foi fortemente cultivado no Vale do Paraíba, rumou posteriormente para o Oeste paulista. Diante deste novo delineamento econômico a Cidade de São Paulo passou a ter papel fundamental na economia nacional. Neste novo contexto o café adquiriu importância tal para o país, que, este passa ser a base do crescimento industrial, porquanto ele proporcionou o pré-requisito elementar de um sistema industrial - a economia monetária. A atividade empresarial ligada a esta cultura torna-se proeminente em relação ao restante do país devido a "intensa operação da economia de mercado, isto é, pela maior lucratividade do café e pelo uso mais completo do dinheiro como meio de troca" (DEAN, 1996, p. 46). Para Milton Santos, São Paulo se torna o pólo dinâmico de grande área do território nacional, graças à monocultura do café.

Mesmo nesta gênese rudimentar da industrialização em São Paulo, fez-se necessário o uso de mãode-obra. Diante deste quadro foram utilizados neste primeiro momento "imigrantes, compondo-se de homens que haviam tentado tratar de cafezais, mas não se haviam dado bem nessa ocupação, e de imigrantes subsidiados que, se bem nunca houvessem assinado contratos, tinham conseguido permanecer nas cidades" (DEAN, 1996, p. 59).

Assim, a análise de Dean contribui também para respaldar a epidemia de urbanização de Monbeig, pois no inicio "a indústria brasileira continuou, pois, a depender primordialmente de seu enorme estoque de recursos vegetais nativos para ter combustível" (DEAN, 1996, p. 87). Esse autor destaca que os 390 $\mathrm{km}^{2}$ de Mata Atlântica existente no inicio do século XX equivalia a mais de 6,2 bilhões de toneladas de carvão e que o consumo de lenha passou de $0,4 \mathrm{~m}^{3}$ a 2,2 $\mathrm{m}^{3}$ per capita em 1950. Mensuração que serve claramente para confirmar a aceleração do uso de faixas remanescentes e relativamente intactas e transformação da Mata Atlântica em fonte de energia e calor, pois, somente em 1950 as indústrias metalúrgicas de São Paulo e Rio de Janeiro chegaram a uma demanda de 140 km². (DEAN, 1996, 266268).

A mão de obra estrangeira foi insuficiente e os migrantes nacionais vieram numerosos para São Paulo. A expansão industrial absorveu praticamente a maior parte da mão de obra migrante de outras regiões brasileiras, fenômeno acentuado com a queda do café, visto que em 1929 a produção industrial paulista passou a responder por 37,5\% do total do país. A imagem da mancha urbana em 1930 é reveladora desse processo.

Paulatinamente o centro da economia nacional transmuta do campo, principalmente da economia cafeeira para a cidade, que recebeu várias correntes migratórias passando de poucas dezenas de milhares de pessoas no fim do século XIX, para aproximadamente 18 milhões de pessoas em nossos tempos. Em 20 anos a cidade de Sao Paulo, antes restrita ao sitio localizado entre os rios Tietê e Pinheiros ultrapassa rapidamente estes limites naturais e transforma-se em um espaço dominado pelos bairros de trabalhadores atraidos pela possibilidade de trabalhar na industria. Em 1952, uma pequena area além do rio Tietê foi incorporada e com bairros dispersos; em 1972 a cidade torna-se uma massa compacta:

Queremos entender este processo respaldando-nos em uma abordagem ambiental, visto que estas pessoas que vieram aqui morar corroboraram com a devastação proporcionada pela industrialização cujas habitações, que no limite invadiram áreas que antes faziam parte do cinturão verde da cidade de São Paulo, propiciando numerosos problemas ambientais questionados ao longo do nosso estudo. 

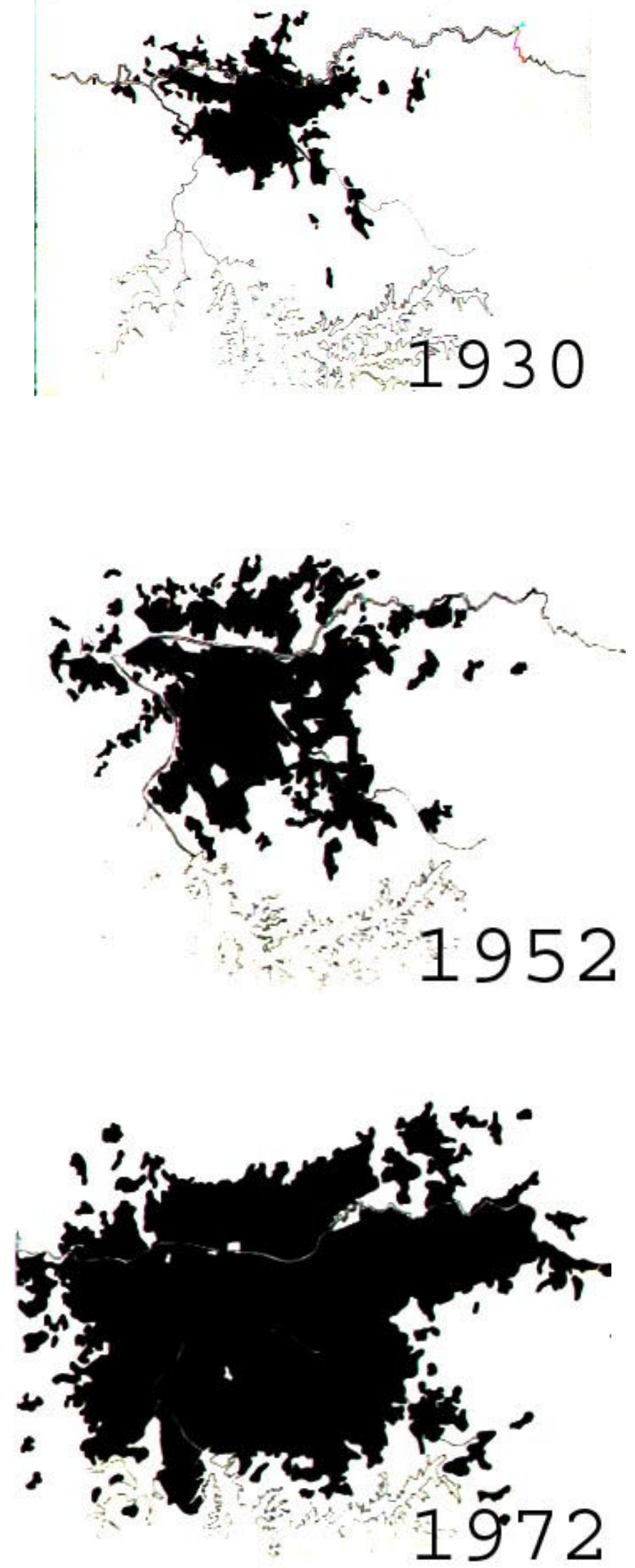
Ainda que no limiar do século XXI São Paulo se enquadre nos critérios de cidade mundial, ela é uma cidade fragmentada. Fragmentada porque se constrói por meio de visões e interesses imediatos e individuais. Para Damiani (2005) a modernidade de São Paulo é incompleta porque, na verdade, ela expressa mais as dificuldades do moderno, pelo crescimento rápido da cidade, com abertura de vias, de ruas, construções, loteamentos, onde não havia ainda uma consciência dos interesses coletivos pelos indivíduos e da predominância, nos negócios imobiliários das pequenas empresas familiares.

Como elaborar políticas que se integrem em conteúdos, que não se contradigam se no espaço existe múltiplas cidades dentro de uma única?

Pouco importa o período pelo qual São Paulo passou, mas, desde a pequena cidade de taipa até a metrópole, a questão da qualidade do ambiente local foi pouco considerada. O padrão de urbanização entre as décadas de 1940 e 1960 foi disperso, pouco denso e precário, formando uma mancha urbana desarticulada, cujo centro cresceu $171 \%$ e a periferia $364 \%$, composto essencialmente de população de baixa renda (BIDERMAN, MEYER e GROSTEIN, 2004). As favelas representam parte dessa urbanização precária. Saraiva e Marques (2008) indicam que, em 1940, existiam apenas 4 favelas.

São Paulo se transforma em região metropolitana pela Lei Complementar Federal nº 14, de 1973 porque o processo de conurbação e dependência com os municípios limítrofes, o crescimento acelerado pela intensa migração necessária ao desenvolvimento das atividades econômicas, resgatando o que Damiani considera como a melhor explicação para a rápida urbanização de São Paulo. Em 1973, segundo Taschner (2000, in SARAIVA e MARQUES, 2008) as favelas alojavam cerca de 1\% da população do município de São Paulo, algo em torno de 70 mil habitantes.

Dois anos após instaura-se o Decreto Lei 1.413, de 14 de Agosto de 1975, sobre o controle da poluição do meio ambiente provocada por atividades industriais e, somente em 1980, com a lei 6803/80, foi estabelecido o zoneamento em áreas críticas de poluição, definindo-se as primeiras restrições legais ao uso do solo metropolitano.

As restrições legais tanto do uso do solo metropolitano quanto pelo Código Florestal (lei 4771 de 1965) que normatiza a proteção de mananciais, margens de cursos d'água e encostas de morros não impediram, no entanto, que o crescimento das favelas em São Paulo aumentasse para $9 \%$ da população (812 mil) em 1987. Segundo Saraiva e Marques (2008, p. 4), os números obtidos pelo Censo do IBGE e pelos métodos da Prefeitura são desiguais e decorrem dos conceitos e interpretações do que seja a população em habitações subnormais ou moradora em favelas, respectivamente:

Tabela 1. Evolução da população favelada no Município de São Paulo, 1973-2000

\begin{tabular}{|cccc|c|cc|c} 
ano & população total & $\begin{array}{c}\text { pop. } \\
\text { subnormal } \\
(2)\end{array}$ & $\begin{array}{c}\text { população } \\
\text { favelada }\end{array}$ & $\begin{array}{c}\text { \% pop. } \\
\text { favelada }\end{array}$ & $\begin{array}{c}\text { taxa de } \\
\text { período }\end{array}$ & $\begin{array}{c}\text { taxa de } \\
\text { cresc. aa - } \\
\text { favelas }\end{array}$ & $\begin{array}{c}\text { cresc. aa - } \\
\text { total }\end{array}$ \\
1973 & $6.560 .547^{(1)}$ & - & $71.840^{(3)}$ & $1,1 \%$ & - & - & - \\
1980 & $8.558 .841^{(2)}$ & 375.023 & & $4,4 \%$ & $1973-80$ & $20,16 \%$ & $3,00 \%$ \\
1987 & $9.210 .668^{(1)}$ & $530.822^{(6)}$ & $812.764^{(4)}$ & $8,8 \%$ & $1980-87$ & $8,97 \%$ & $0,82 \%$ \\
\hline 1991 & $9.644 .122^{(2)}$ & 647.400 & $891.673^{(5)}$ & $9,2 \%$ & $1987-91$ & $1,03 \%$ & $0,51 \%$ \\
\hline 2000 & $10.338 .196^{(2)}$ & 896.005 & $1.160 .597^{(5)}$ & $11,2 \%$ & $1991-00$ & $2,97 \%$ & $0,78 \%$ \\
\hline
\end{tabular}

Fontes: (1) Fundação SEADE: 1973, 1987.

(2) IBGE: Censo Demográfico 1980, 1991, 2000.

(3) PMSP / COBES. Equipe de Estudos e Pesquisas. Favelas no Município de São Paulo. 1973,1980. (4) PMSP. SEHAB. HABI. Div. Téc. de Planejamento. Coord. Inf. Téc. e Pesquisas. Censo das Favelas do Município de São Paulo. 1987.

(5) Estimativas CEM.

(6) Dados interpolados geometricamente 


\section{Proteção por etapas: histórico da construção e movimentos de resistência}

A Reserva da Biosfera do Cinturão Verde da Cidade de São Paulo (RBCV) foi reconhecida pela UNESCO em 09 de junho de 1994, como parte integrante da Reserva da Biosfera da Mata Atlântica e abrange uma área de 1.540.032 ha, e incluindo a área urbana, o total de 1.760.311 há, abrangendo o território de 73 municípios e $10 \%$ da população nacional.

A RBCV abrange também um grande número de áreas protegidas pela legislação Federal, Estadual e Municipal, em diferentes categorias de proteção ao patrimônio ambiental, cultural, histórico, artístico paisagístico e as terras indígenas. Considerando a importância da situação fundiária nas ações de defesa do patrimônio envolvido, o conjunto de instrumentos legais abrange áreas de domínio público e privado. Além das Unidades de Conservação de Proteção Integral (Parques Estaduais, Estações Ecológicas e Reservas Florestais) e Unidades de Conservação de Uso Sustentável (Áreas de Proteção Ambiental) incluem as Áreas Naturais Tombadas, as Áreas de Proteção a Mananciais, as Áreas de Preservação Permanente, as Reservas Particulares de Patrimônio Natural e Reserva Legal averbada.

A RBCV teve origem no movimento social contrário à construção do Rodoanel (trecho norte) que conseguiu juntar 150 mil assinaturas em favor da criação da Reserva e paralisação do Rodoanel. O Governo do Estado de São Paulo apoiou esse movimento pela conservação ambiental.

Quando a nova lei do SNUC foi aprovada em 2000, a Reserva da Biosfera passou a integrar o modelo brasileiro de proteção in situ. A Reserva da Biosfera busca a implantação de um modelo de gestão integrada, participativa e sustentável a ser adotado internacionalmente. Esta definida, nessa lei, que a Reserva tem como objetivos a "preservação da diversidade biológica, o desenvolvimento de atividades de pesquisa, o monitoramento ambiental, a educação ambiental, o desenvolvimento sustentável e a melhoria da qualidade de vida das populações" (SNUC, 2000). Ainda de acordo com o SNUC (2000), a reserva da biosfera é constituída por áreas de domínios que podem ser público ou privados, podendo ser integrada por unidades de conservação já existentes, respeitando as normas de cada categoria.

As funções atuais de uma Reserva da Biosfera abrangem três categoriais: a conservação, o desenvolvimento e o apoio logístico. Quanto à Conservação, visa proteger os recursos genéticos, as espécies, os ecossistemas e as paisagens. Do ponto de vista do desenvolvimento: visa promover o desenvolvimento econômico e humano sustentável e quanto ao apoio logístico objetiva respaldar atividades de pesquisa, educação, formação e observação permanente relacionadas com atividades de interesse local, nacional e mundial, destinadas à conservação e ao desenvolvimento sustentável.

Dentro da área da RBCV escolhemos apenas duas áreas, o Parque Estadual da Cantareira e a APA Capivari - Monos (Figura 1). Passemos a contextualização de suas origens:

\section{De área tombada ao Parque da Cantareira}

A área do atual Parque da Cantareira foi tombada no final do século XIX, como forma preventiva de garantir o abastecimento de água da cidade de São Paulo, através das represas do Engordador, Barrocada e Cabuçu.

A partir de 1894, a maria-fumaça começou a contribuir com a poluição na Cantareira. A intenção na construção desta linha era ligar o centro da cidade à Serra da Cantareira, expandindo o centro urbano. A necessidade de integrar os pontos mais longínquos da cidade e também o abastecimento de água para a crescente indústria paulista levaram a construção da estrada de ferro, visto que, até 1895 era o meio de levar materiais para a construção do sistema de abastecimento de águas da Cantareira. Começa ai o embate entre o ambiente natural e o construído. O "Tramway" funcionou até 1965, como trem de passageiros, sendo substituído pelas linhas de ônibus até os nossos dias.

O Parque nasce em um período de intensa industrialização e aumento populacional, visto que a década de 1960 proporcionou índices elevados de aumento da população. O ritmo de crescimento da periferia era mais acelerado que o centro, além disso, eram as populações mais pobres que ocupavam as regiões mais distantes. 


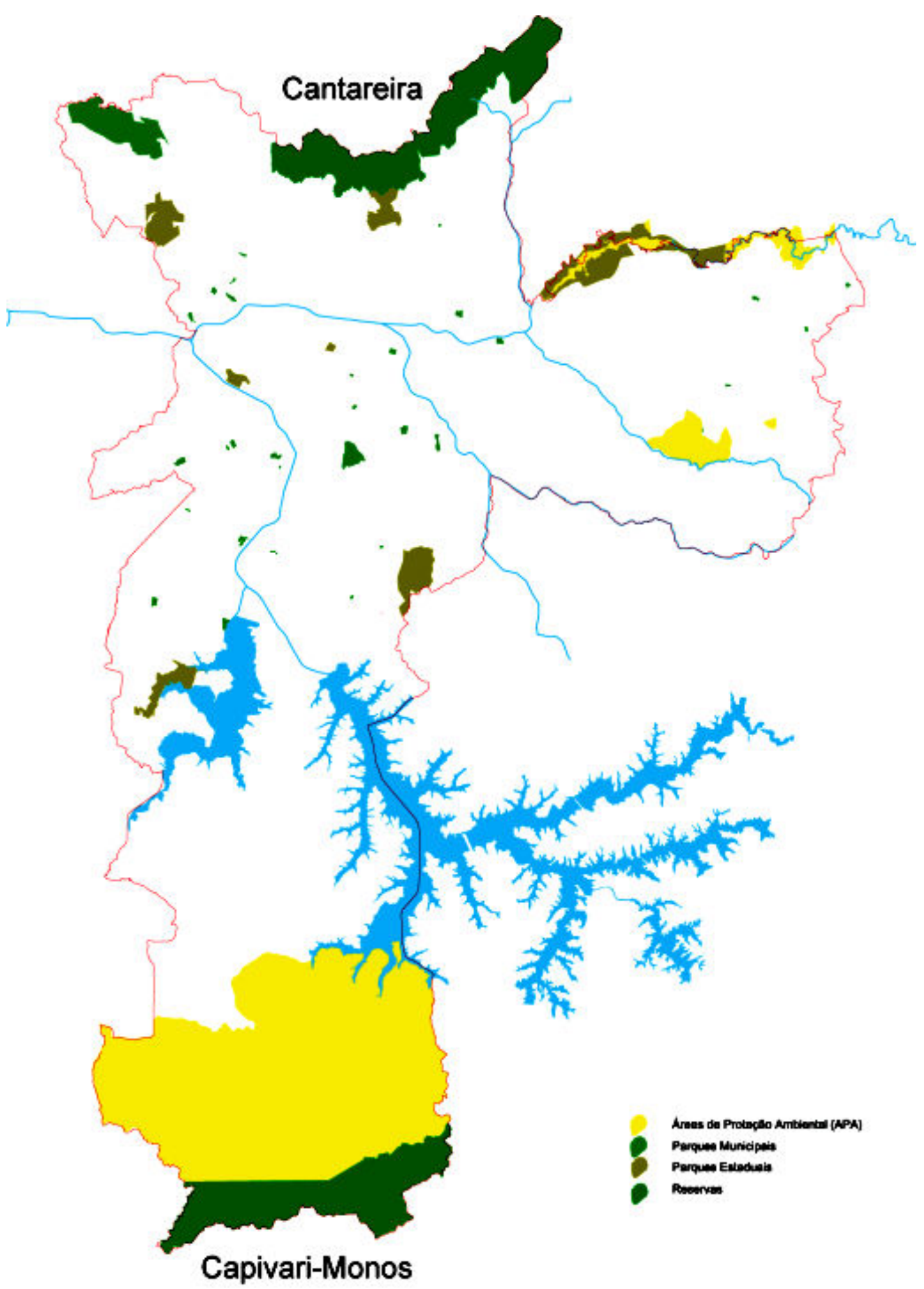

Figura 1: Localização - Parque Estadual da Cantareira e a APA Capivari - Monos 
O Parque Estadual da Cantareira (PEC) tem um diferencial em relação às demais áreas de conservação do país. Trata-se da relação entre a região metropolitana de São Paulo, que teve um crescimento intenso, e uma área de preservação permanente, com uma relevância incomensurável, tanto como manancial, quanto como exemplar remanescente da Mata Atlântica.

Foi o decreto 41.626/63, que criou o PEC, que tem uma área de 7.961.52, sendo considerada a maior floresta tropical nativa do mundo situada dentro de perímetro urbano.

Sua área está contida em quatro municípios da região metropolitana de São Paulo, são elas: Caieiras, Guarulhos, Mairiporã e São Paulo. São quatro visões sobre o mesmo objeto, sendo que cada um destes municípios tem uma relação determinada e diferenciada com o PEC, no sentido de conter o crescimento das respectivas cidades em direção a esta unidade de conservação, o que dificulta sobremaneira qualquer atuação articulada, especialmente quanto a sua conservação.

O PEC integra o sistema Cantareira de águas, responsável por 51\% do abastecimento da cidade de São Paulo. Nele se encontra valiosa biodiversidade, onde são encontradas diversas espécies da fauna e da flora nativa, como por exemplo, o bugio, o veado mateiro, a preguiça, o quati, a jararaca, além de samambaias-açua, figueira, a embaúba, etc..

A dinâmica demográfica e social caracteriza o município de São Paulo há mais de um século, refletindo um período de crescimento populacional exacerbado e um avanço da ocupação que reduz principalmente em áreas periféricas e de mananciais, a cobertura vegetal, ameaçando os últimos remanescentes de recursos naturais da metrópole.

A taxa de crescimento demográfico configura-se como importante indicador de sustentabilidade ambiental de uma cidade quando associado às formas de utilização dos recursos naturais. Em São Paulo e em toda a região metropolitana, um dos aspectos mais impressionantes do processo de urbanização refere-se à rapidez das alterações nas taxas de crescimento da população ao longo do tempo. A região com crescimento demográfico mais significativo em São Paulo está no entorno do Parque, do extremo leste e sul do município, bairros como: Anhanguera, Brasilândia, Capão Redondo, Campo Limpo, Cidade Tiradentes, Grajaú, Guaianazes, Iguatemi, Itaim Paulista, Jaraguá, Jardim Ângela, Lageado, Marsilac, Parelheiros, Pedreira, Perus, São Rafael, Tremembé, Vila Andrade e Vila Jacuí (SVMA).

Esse processo de avanço da cidade em direção ao Parque Estadual da Cantareira acarreta diversos impactos na área natural. Segundo o Atlas Ambiental do município de São Paulo (2004), 48\% do território do município apresentam carência significativa de cobertura vegetal de qualquer tipo. Em contrapartida, 33\% do município são cobertos por maciços florestais. Distritos como Tremembé e Jaçanã são submetidos à intensa pressão de ocupação, visto que concentram, juntamente com os distritos de Parelheiros, Marsilac, Grajaú, Jardim Ângela e Perus, 75\% desse tipo de cobertura vegetal.

A conservação de uma área natural, segundo Silva (2000), é complementada pelo uso adequado da terra ao seu redor, pois certas atividades realizadas fora de seu domínio podem repercutir de forma negativa em seu interior, degradando-a. Áreas protegidas são gerenciadas como locais isolados do contexto regional ou local, mas estão em constante conexão com seu entorno através de relações econômicas, sociais, culturais e ecológicas. O PEC, nestes 40 anos de existência sofreu uma série de interferências por estar próximo da área urbana, como as ligadas ao abastecimento de água, energia, transporte, moradia, entre outros.

\section{Especulação imobiliária e poder público}

Atualmente algumas empresas procuram vincular seus produtos a práticas de responsabilidade sócio ambiental, criando produtos com o Selo verde de Qualidade (ISO 14.000) e usando matérias primas certificadas.

É provável que para a maioria dos empresários, motivações menos confessáveis eram mais determinantes. Embora superficial, a preocupação do público pela preservação da natureza era agora suficientemente ativa para gerar lucros.'Quando você consegue associar seu produto a uma mensagem ecológica', explicava um executivo de marketing, 'o retorno, tanto em vendas como em imagem, é fantástico'.de 
modo mais defensivo, as companhias que já haviam tido problemas com suas imagens poderiam salválas com uma campanha verde. (DEAN, 2002, p. 348).

Porém, a mídia imobiliária age diametralmente contra, visto que, esta usa a temática ambiental para vender casas e apartamentos próximos a áreas de conservação, como o caso do Parque da Cantareira.

Os bairros de classe média do entorno, por exemplo, elegem como diferencial a sua localização próxima a áreas de preservadas. A especulação imobiliária atua nestas áreas de forma mais incisiva.

Não obstante, os bairros do entorno sul, bairros considerados de classe baixa, estão entre os que mais crescem no município de São Paulo.

Esta procura de áreas periféricas para moradia das classes baixas deve-se a dificuldade para se construir nos centros altamente urbanizados como os bairros já estruturados. Isto leva a população menos abastada a morar em áreas mais distantes, como é o caso da face sul do Parque da Cantareira. A facilidade e o baixo custo destes terrenos são agentes facilitadores para a construção de moradias de baixa renda.

O poder público também contribui diretamente em alguns casos para a ocupação de áreas próximas ao PEC, como é o caso do Centro Unificado de Educação (CEU) no jardim Paraná, o qual é um grande equipamento educacional que age como um pólo de atração de contingente populacional, pois estas precisam estar próximas ao CEU para que consigam vagas para seus filhos, induzindo assim, a ocupação em áreas de amortecimento do Parque, que, embora não regulamentada, deveria circundá-lo..

\section{APA Municipal Capivari-Monos}

AAPA municipal Capivari-Monos, ultima barreira natural da Região Metropolitana de São Paulo, inviabiliza a chegada da urbanização até a Serra do Mar, também é pertencente ao cinturão verde de São Paulo. Foi criada no intuito de proteger os mananciais, destinados ao abastecimento de água potável que, segundo Bellenzani (2001) são protegidos pela Legislação Estadual de Proteção aos Mananciais, vigente desde 1975 e revista em 1997. Esta legislação, ressalta ainda Bellenzani (2001), regulamenta o uso do solo nas bacias hidrográficas responsáveis pelo abastecimento hídrico da metrópole.

Mesmo com esta lei a área de proteção aos mananciais vem sendo degradada, paulatinamente, devido principalmente à expansão urbana. A urbanização frágil impetrada na periferia de São Paulo avança sobre as regiões rurais, possibilitando o desmatamento da Mata Atlântica, o que evidencia os riscos que as reservas, que contém no seu interior mananciais, estão convivendo.

Diante deste quadro, a Prefeitura do Município de São Paulo criou por Lei Municipal, em junho de 2001, a Área de Proteção Ambiental - APA - Municipal do Capivari-Monos, no extremo Sul do Município.

Os objetivos da APA são os de proteger a biodiversidade, dos recursos hídricos e do patrimônio histórico e cultural, igualmente, a elevação da qualidade de vida da população, além da contenção da expansão urbana e a manutenção do caráter rural.

Porém, a região onde esta localizada a APA Capivari - Monos, o bairro de Parelheiros, é a que mais cresce no município de São Paulo: 84, 9\% na década de 90 enquanto no território municipal, como um todo, o crescimento populacional caiu na década de 1990, uma tendência que já era perceptível nos anos 1980. É, portanto, um fenômeno de grande migração interna que esta atingindo toda a extremidade sul do município de São Paulo envolvendo toda a bacia dos rios Capivari e Monos, além de partes das bacias hidrográficas dos reservatórios Guarapiranga e Billings. A região da APA abrange os seguintes bairros: Barragem, Cidade Nova América, Vargem Grande, Engenheiro Marsilac, Evangelista de Souza, Jardim dos Eucaliptos, Gramado, Ponte Seca, Ponte Alta e Emburá do Alto. A APA Capivari - Monos pode ainda ser considerada como zona de amortecimento do Parque Estadual da Serra do Mar, constituindose em uma fronteira, a qual age como anteparo a expansão urbana, desestimulando seu avanço sobre a MataAtlântica.

Olhando o fenômeno com lentes ambientais percebemos que "o processo de mudanças sociais e ecológicas causado por perturbações (uma nova ocupação e/ou construção de um objeto novo: uma usina, uma estrada ou uma indústria) no ambiente" (Coelho, 2000, p. 24) indica uma alteração substancial 
do ambiente natural, pois a instalação de novas residências representa um aumento no impacto ambiental (retirada de vegetação, movimentação de terra para construção de ruas e acessos, aterramento das bordas das represas com novos loteamentos, expulsão da fauna existente no local pela redução do seu habitat, aumento da circulação, etc.).

AAPA compreende toda a bacia hidrográfica do Capivari-Monos e parte das bacias hidrográficas do Guarapiranga e Billings e possui uma extensão territorial de $251 \mathrm{Km}$, o que corresponde a aproximadamente um sexto do território do município de São Paulo.

A bacia hidrográfica do Capivari-Monos está dentro da APA, sendo que as bacias hidrográficas do Guarapiranga (cabeceiras do rio Embu- Guaçu, ao Sul da bacia) e Billings (braço Taquacetuba) estão parcialmente contidas. O rio Capivari, de vertente marítima, é parcialmente revertido para o reservatório Guarapiranga, através de uma estação elevatória construída na década de 70.

Aárea concentra os últimos remanescentes de Mata Atlântica do Município de São Paulo. Dados da Secretaria Municipal do Verde e Meio Ambiente - SVMA(1997), revelam que a vegetação nativa é o tipo, ainda mais presente na APA ( cerca de 73\% do território, incluídos campos naturais), indicando que, felizmente, trata-se de uma área ainda relativamente preservada, apesar de estar dentro do município de São Paulo.

Os loteamentos encontrados correspondem a cerca $4 \%$ do território. As áreas mais densamente ocupadas estão no entorno da bacia da Billings e na região da Barragem, divisor de águas desta e da bacia Capivari-Monos e Billings. Segundo estimativa da SVMA, vivem atualmente cerca de 65.000 pessoas na APA, a grande maioria em loteamentos irregulares. O grande paradoxo na área de proteção aos mananciais é por um lado,

a precariedade dos assentamentos irregulares é social e ambientalmente insustentável, acarretando graves problemas de saúde pública e gerando justas reivindicações dos moradores. Por outro lado, o atendimento à demanda pela melhoria da infra-estrutura nesses assentamentos é,além de proibida pela legislação vigente, certamente indutora da expansão urbana desordenada, perpetuando assim processo perverso de degradação ambiental e exclusão social (BELLENZANI, 2001)

Parte das 65 mil pessoas são residentes da Cratera da Colônia, que recebeu o nome de Vargem Grande ao ser transformado em bairro.

\section{A Cratera da Colônia}

Em 1989, iniciou a ocupação do Condomínio Vargem Grande, um enorme bairro irregular que se formou nos limites da cratera ${ }^{1}$. Atualmente este condomínio abriga cerca de 40 mil pessoas.

Além dos imóveis construídos em regime de autoconstrução, que exerce forte pressão antrópica, contribuindo decisivamente para a degradação ambiental da APA, principalmente pela falta de infra estrutura, também há no local uma casa de detenção construída pelo Estado, responsável por "dejetos jogados em um canal artificial que desemboca no Ribeirão Vermelho (afluente da Billings), passando antes por dentro da Vila de Vargem Grande." Desta forma o Estado contribui, não só para a degradação, como também pode contaminar os poços de água das famílias residentes na Colônia. Há “casos de hepatite, tuberculose, verminoses, infecções intestinais, entre outras doenças.” ( GAFFO, 1998, p. 59)

Apesar de poluir o rio, a Casa de detenção jamais foi multada. Muito menos por causar doenças às pessoas do loteamento. Por ser o loteamento clandestino, não pode receber infra-estrutura, como transporte, energia, esgoto, calçamento, etc. Não obstante, em nossas visitas de campo verificou-se existência de ônibus, energia elétrica, coleta de lixo e início de calçamento. A clandestinidade de hoje torna-se argumento de discurso político, defensor da regularização..

A fragmentação urbana encontra-se neste local em seu estágio mais exacerbado. Pessoas que levam horas para se deslocar de suas casas para o trabalho e do trabalho para casa, as quais não dispõem do mínimo necessário para o morar com dignidade. Pessoas deserdadas pelo Estado e que se apegam à primeira possibilidade de construir a casa própria. 


\section{Considerações Finais}

A urbanização impetrada na cidade de São Paulo propiciou uma ocupação desordenada e com alto custo social. É indubitável a potencializaçao da degradação ambiental que a cidade e também a RMSP vive desde os primórdios da industrialização. As duas áreas escolhidas para estudo são casos típicos da ocupação desordenada, na qual importava apenas a localizaçao das pessoas e das atividades econômicas. O Parque Estadual da Cantareira e a APA Capivari-Monos apresentam especificidades distintas em relação as suas ocupações, contudo o ponto convergente de ambas esta no papel estratégico de contenção urbana e para o fornecimento de água para o abastecimento da cidade porquanto, executando esta tarefa a contento, tanto a flora como a fauna destas regiões estariam preservadas. Durante as décadas iniciais do século passado o papel mais importante da cidade era de dar suporte à consolidação da indústria nascente, tendo pouco valor areas destinadas à preservaçao ambiental. Posicionamento que se inverte ao final do século, com a valorizaçao do meio ambiente, como dimensao da qualidade de vida urbana e como mercadoria para a expansao imobiliaria.Assim, ao mesmo tempo em que instituiçoes governamentais se responsabilizam pela manutenção da conservação ambiental, o incentivo para a ocupação de áreas preservadas vem diretamente do poder público, ao construir grandes equipamentos no entorno destas áreas, capazes de incentivar grandemente o avanço urbano. Aos incentivos publicos agregam-se, mais recentemente, aqueles dos agentes imobiliarios privados.

As politicas ambientais implantadas foram marginais. A articulação dessas políticas públicas com outras setoriais, como a de habitação, em primeiro plano, seguida pela de esgoto e transportes é urgente e deve coibir esta prática de desvalorização do meio ambiente, tão recorrente em nossa história e a qual ensejou o quase desaparecimento da Mata Atlântica.

\section{Notas}

Cratera é uma subsidência originada pelo impacto de um meteoro, segundos alguns estudos. Não há consenso sobre a veracidade desta informação. A cratera mede 3,6 quilômetros e tem profundidade que chega a cerca de 400 metros.

\section{Agradecimentos}

Artigo resultante de pesquisa científica (Social Exclusion,Territoires et Urban politiques - SETUP), apresentado no Seminário internacional "Políticas urbanas, territórios e exclusão social: uma comparação India-Brasil", com financiamento pelaANR (Agence Nationale de la Recherche-França), o qual permitiu a realização de trabalho de campo, de entrevistas a atores governamentais responsáveis pela gestão do Parque Estadual da Cantareira e da APA Capivari-Monos. Agradecemos contribuiçoes recebidas de Carla Moura de Paulo e Livia Simanauskas.

\section{Referência Bibliografia}

AYRES, Ana Carolina Moreira. O ciclo da Caapora; a RMSP e o Parque Estadual da Cantareira. São Paulo:Annablume, 2008

BELLENZANI, M.L.R. A Apa municipal do Capivari-Monos como uma estratégia para a proteção dos mananciais da região Metropolitana de São Paulo. Dissertação de Mestrado. USP. Programa de Pós Graduação em Ciência Ambiental, 2001.

BOMBONATTO JR, C. E BREGA FILHO, D. Do saneamento básico ao saneamento ambiental. Revista DAEE/SABESP, 169 (53), 4 - 14, 1993.

CARLOS, A.; OLIVEIRA, A (orgs). Geografias de São Paulo. São Paulo: Contexto,2004

CASSETARI, O. E VIOL, J. A. Um exemplo na prática. Revista DAEE/SABESP, 166. (53) 21 - 31, 1992. 
DEAN, Warren. A ferro e fogo: a história e a devastação da Mata Atlântica Brasileira. São Paulo: Cia das Letras, 1996.

DE PAULO, Carla Moura. Pressões em área de proteção ambiental decorrentes da ocupação urbana: uma análise da APA Capivari - Monos. Monografia de iniciação científica. PIBIC/EACH/USP, março.2008. GAFFO, Leonardo. Mitos e ritos na relação homem/natureza: um caso - A ocupação da cratera de Colônia - Parelheiros - São Paulo, 1998 - Dissertação (mestrado). FFLC - Faculdade de Filosofia letras e Ciencias Humanas.

JORGE, Janes. A procura de um reencontro: o Tiete e os moradores de São Paulo. In História ambiental paulista: temas, fontes, métodos. São Paulo: Editora SENAC, 2007

MARTINEZ, Paulo enrique. História ambiental paulista: temas, fontes, métodos. São Paulo: Editora SENAC, 2007

SÃo PAUlo (Município). Atlas Ambiental do Município de São Paulo - o verde, o Território, o ser Humano. SP:SVMA, 2004.

SILVA, DIMAS A Evolução do uso e ocupação da terra no entorno dos Parques Estaduais da Cantarteira e Alberto Lofgren e impactos ambientais decorrentes do crescimento metropolitano. São Paulo: FFLCH/USP, 2000. Dissertação de Mestrado.

SILVA, Sergio.Expansão cafeeira e origens da indústria no Brasil. 7. ed. São Paulo: Alfa-Ômega, 1976.

SIMANAUSKAS, Lívia. Planejamento urbano e conservação de florestas periurbanas: um estudo de caso sobre a zona de amortecimento da ocupação sul do Parque Estadual da Cantareira. Monografia de iniciação científica. PIBIC/EACH/USP. Junho de 2008

SPOSATI, A. (coord.) et alii Mapa da inclusão/exclusão social em São Paulo. Núcleo de Seguridade e Assistência Social do Programa de Estudos Pós-Graduados em Serviço Social da PUC/SP. São Paulo: PUC (cd rom), 1996.

SVMA, Caracterização sócio ambiental da APA Municipal do Capivari-Monos: relatório preliminar. São Paulo: Secretaria Municipal do Verde e do Meio Ambiente(relatório),1997.

As imagens de 1930, 1952 e 1972 foram obtidas no site www.cdcc.usp.br/.../art_23/sampahoje.html

Trabalho enviado em maio de 2009

Trabalho aceito em setembro de 2009 